\title{
The Capabilities of Interference Microscopy in Studying the in vitro State of Erythrocytes Exposed to Low-1ntensity Laser Radiation for Stress Correction
}

DOI: $10,17691 / \mathrm{stm} 2018.10 .4 .09$

Received June 1, 2018

A.V. Deryugina, DSc, Head of the Department of Physiology and Anatomy,

Institute of Biology and Biomedicine";

M.N. Ivashchenko, PhD, Associate Professor, Department of Biochemistry named after G.Ya. Gorodisskaya2;

P.S. Ignatiev, PhD, Head of Medical Device and Microscopy Department3;

M.N. Talamanova, PhD, Associate Professor, Department of Biochemistry and Biotechnology';

A.G. Samodelkin, DSc, Professor, Head of the Department of Animal Physiology and Biochemistry ${ }^{4}$

National Research Lobachevsky State University of Nizhny Novgorod, 23 Prospekt Gagarina, Nizhny Novgorod, 603950, Russia;

2Privolzhsky Research Medical University, 10/1 Minin and Pozharsky Square, Nizhny Novgorod, 603005, Russia;

${ }^{3}$ Production Association "Ural Optical and Mechanical Plant named after Mr. E.S. Yalamov", 33B Vostochnaya St., Ekaterinburg, 620100, Russia;

${ }^{4}$ Nizhny Novgorod State Agricultural Academy, 97 Prospekt Gagarina, Nizhny Novgorod, 603107, Russia

The aim of the investigation was to study the corrective action of low-intensity laser radiation on the in vitro morphofunctional state of stressed erythrocytes using interference microscopy.

Materials and Methods. Blood samples of intact and stressed rats exposed to low-intensity laser radiation (LILR) were studied in experiments in vitro. The wavelength of LILR radiation was $890 \mathrm{~nm}$. Erythrocyte morphology was studied using laser interference microscopy, malondialdehyde and adenosine triphosphate concentrations were assessed spectrophotometrically.

Results. The action of LILR was found to cause no significant changes in the discoid form of erythrocytes and cellular metabolic processes, though it resulted in the appearance of projections on the surface. Exposure to stress promoted a decrease in discocyte count and a significant increase in echinocytes, stomatocytes and degenerative forms of cells with altered microrelief, which was combined with an increase in oxidation processes. The effect of LILR on blood samples of stressed animals led to a decrease in pathological forms of erythrocytes and restoration of cell surface architectonics.

Key words: laser interference microscopy; in vitro state of erythrocytes; low-intensity laser radiation; stress.

\section{Introduction}

The erythrocyte is a universal model to study the processes occurring on the cell membrane affected by a variety of agents. A detailed investigation of changes in morphological and functional parameters of erythrocytes under the influence of various stimuli allows us to determine the possible consequences better and find the most effective ways to correct them.

Special attention should be paid to studying the effect of stress on erythrocytes, since stressful events are an integral part of human life today and minimization of their effect is particularly relevant [1]. Search for pharmacological and physical means and methods to increase cellular adaptation reserve plays an important role in solving this problem.

Today, numerous pharmaceuticals include a large number of different products whose use may reduce the central nervous system response to incoming stimuli, prevent significant catecholamine release and the development of hypermetabolic state [2]. However, pharmacotherapy often produces side effects of various degrees, which necessitates search for nondrug methods. The use of low-intensity laser radiation (LILR) which proves to be an effective and affordable way to treat various pathologies [3] is challenging in this respect. However, the possible mechanisms of biological action of laser radiation on body cells affected by stress remain open to question [4].

Analysis of current scientific trends in visualization of biological objects shows that the dominating position is held by latest technologies providing high accuracy, sensitivity, efficiency, informative value and possibility to objectivize scientific information, identify and evaluate new aspects of various factors influencing the morphological and functional parameters of cell objects under study.

Laser interference microscopy based on the multi-

Corresponding author: Marina N. Ivashchenko, e-mail: kafedra2577@mail.ru 
faceted optical-geometric approach to intravital analysis of morphological and functional characteristics of peripheral blood corpuscles is quite promising in this respect. An important feature of this technology is that optical path difference value recorded in the interferometer allows obtaining quantitative information about three-dimensional refractive-index distribution and morphology of a biological object [5].

All of the above has determined the line of this investigation and methodological approaches to the implementation of scientific tasks.

The aim of the investigation was to study the corrective effect of low-intensity laser radiation on the in vitro morphofunctional state of stressed erythrocytes using interference microscopy.

\section{Materials and Methods}

The object of the study was the whole blood of rats that underwent stress induced by intraperitoneal administration of epinephrine hydrochloride solution $(0.1 \mathrm{mg} / \mathrm{kg})$ in the experimental group and the blood of intact animals (the control group). Each group included 10 specimens.

The study was carried out in accordance with order No. $199 \mathrm{H}$ "On the Approval of the Rules of Good Laboratory Practice" (Russia, 2016) and International Guiding Principles for Biomedical Research Involving Animals (CIOMS and ICLAS, 2012) and complied with ethical principles established by the European Convention for the Protection of Vertebrate Animals used for Experimental and Other Scientific Purposes (Strasburg, 2006). The experimental study involving animals was approved by the Ethics Committee of Nizhny Novgorod State Agricultural Academy.

The blood of the groups under study was exposed to radiation for $15 \mathrm{~min}$ in Petri dishes $3 \mathrm{~cm}$ in diameter. Laser therapeutic apparatus (Uspek; Voskhod, Russia) which is a small-size autonomous matrix of 10 laser diodes was used as a laser radiation source at a distance of $1 \mathrm{~cm}$ from the membrane surface. The radiation wavelength: $890 \mathrm{~nm}$; pulse repetition frequency: $415 \mathrm{~Hz}$; total radiation pulse power: $30 \mathrm{~W}$; the minimum average radiation power density in the plane of the applicator exit window: $193 \mathrm{~mW} / \mathrm{cm}^{2}$; the exit area: $20 \mathrm{~cm}^{2}$. Non-irradiated blood of the same specimens served as control.

Erythrocyte morphology, malondialdehyde (MDA) and adenosine triphosphate (ATP) concentrations in erythrocytes were analysed in all groups. The analysis was performed one hour after exposure to radiation. Before measurement, non-irradiated and irradiated blood was centrifuged three times with saline at $3000 \mathrm{rpm}$ for 10 min.

Ten samples were studied in each series.

Complex erythrocyte phase measurement was performed by means of phase-modulation laser interference microscopy using the MIM-340 microscope
(Ural Optical and Mechanical Plant named after Mr. E.S. Yalamov, Russia). We used laser with $650 \mathrm{~nm}$ wavelength and lens magnification 30 (NA=0.65), horizontal resolution up to $15 \mathrm{~nm}$, vertical resolution $0.1 \mathrm{~nm}$, the ability to control objects with a relief depth up to $600 \mathrm{~nm}$.

CCD video camera VS415U (Videoscan, Russia) with $782 \times 582$ pixels resolution was used to capture images. Recording the native cell morphology without preliminary fixation made it possible to visualize cell modification in real-time, to study cell morphology and dynamics of intracellular processes.

MDA concentration was assessed by the formation of colored trimethine complex with absorption maximum at $532 \mathrm{~nm}$ [6]. The molar extinction coefficient $E=1.56 \cdot 10^{-5}$ $\mathrm{M}^{-1} \cdot \mathrm{cm}^{-1}$ was used to calculate concentration.

ATP concentration was measured by non-enzymatic method in the hemolyzed erythrocyte filtrate [7]. Inorganic phosphorus was measured in the samples by registering the color density on the KFK-3 photometer (Zagorsk Optical and Mechanical Plant, Russia) at $660 \mathrm{~nm}$ wavelength. Phosphorus concentration was determined by the calibration curve using standard $\mathrm{KH}_{2} \mathrm{PO}_{4}$ solution [8].

The results were statistically processed using application software package BIOSTAT and Microsoft Excel. The significance of the differences between means was evaluated using Student's t-test.

\section{Results and Discussion}

Biconcave-shaped erythrocytes, stomatocytes, echinocytes and degenerative forms of erythrocytes were visualized using laser interference microscopy. In the group of intact animals, $89 \%$ of erythrocytes were represented by discocytes, while the cells of echinocytic, stomatocytic, and degenerative forms accounted for $11 \%$. Their exposure to LILR caused no significant changes in cell morphology (Figure 1).

There was a morphological inhomogeneity of the erythrocyte pool affected by stress: decrease in discocyte count, increase in transitional (echinocytes, stomatocytes) and degenerative cell forms (teardropshaped and target cells, spherocytes, and degmacytes).

Exposure of blood samples from stressed animals to LILR led to increase in discocyte count due to significant decrease in echinocytes (2 times as compared to "stress" group indices). At the same time, there was still high content of cells with morphological changes.

The analysis of morphometric parameters carried out using laser interference microscopy made it possible to obtain high-contrast erythrocyte images without treatment with fixatives. Besides, taking into account the inhomogeneous optical density of cell structures, there were built erythrocyte $3 \mathrm{D}$ models providing the opportunity to analyze changes in cell refractive index and showing the changes in intracellular concentration and/or redistribution of substances within the cell [9]. 


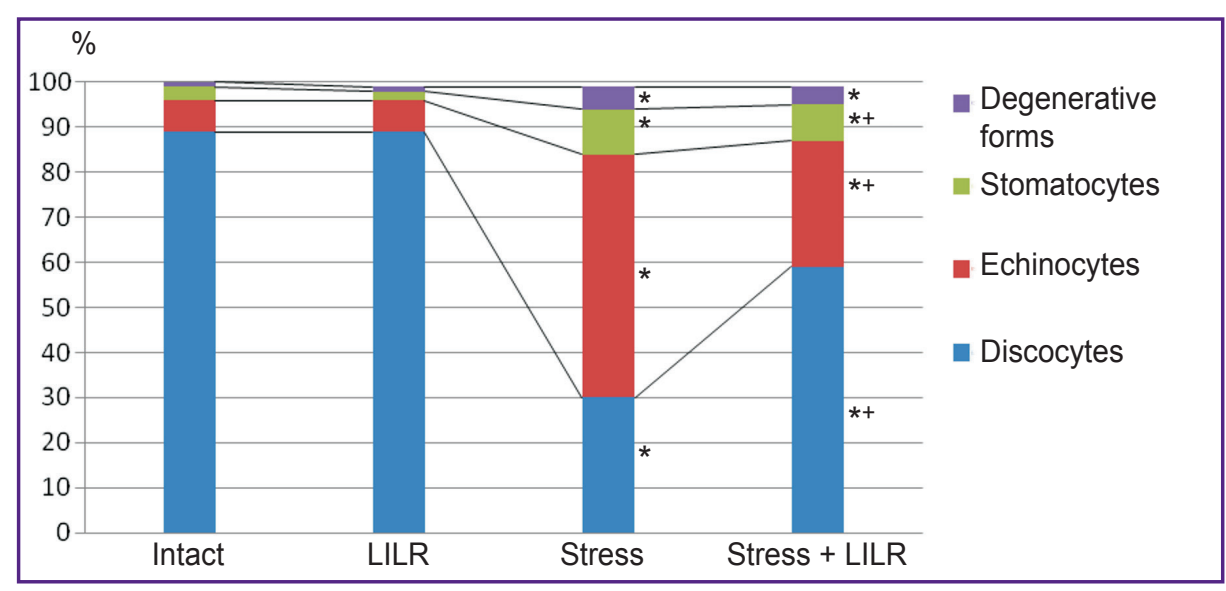

Figure 1. Morphology of erythrocytes in the groups under study

* Statistically significant differences compared to intact group indices; + compared to "stress" group indices; $p<0.05$

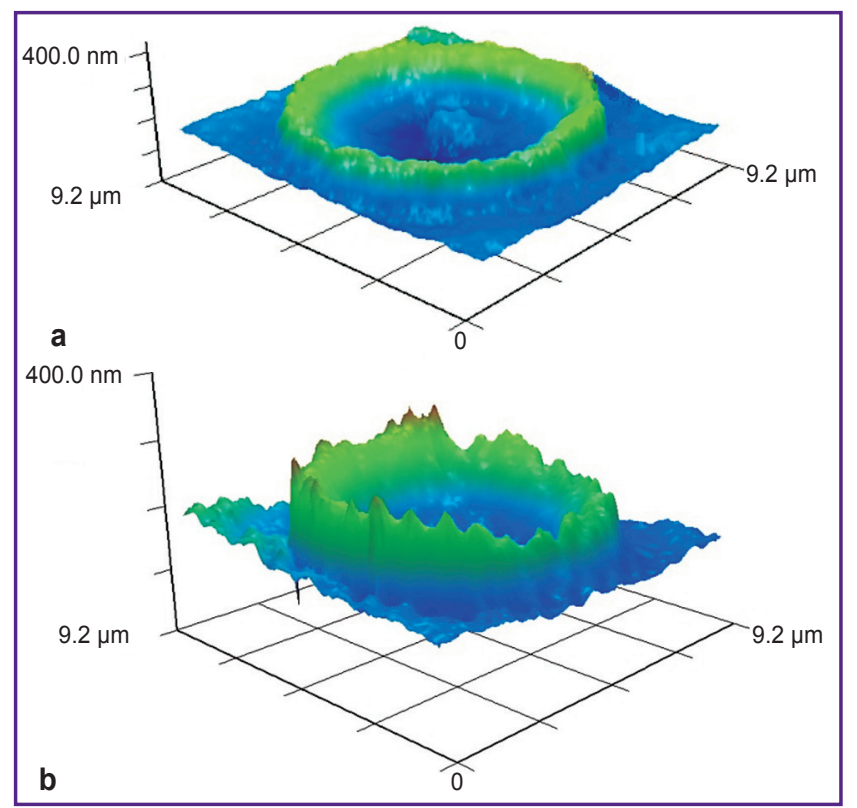

Figure 2. Phase-interference profile of erythrocytes in intact animals:

(a) without exposure to radiation; (b) after exposure of blood samples to LILR

The experimental results showed that the erythrocyte membranes of intact animals had a flat surface, intracellular structures were evenly distributed with evenly distributed hemoglobin (Figure 2 (a)). After exposure to LILR, a large number of projections and bulges were found to appear on erythrocytes (Figure 2 (b)). It should be emphasized that laser interference microscopy revealed significant differences in phase images of intact samples and those exposed to LILR, despite the similarity of discoid shape and size of erythrocytes in these groups.

Phase profiles of erythrocytes in the group of stressed animals unexposed to radiation were characterized by significant number of echinocytes (Figure 3 (a)), altered architectonics and number of projections, increased cell sphericity (Figure 3 (b)). The geometric parameters of a larger number of cells also tended to decrease, while cell volume tended to increase.

The action of LILR on blood samples from stressed animals resulted in reduction of stomatocyte and echinocyte transformation and restoration of discoid shape (Figure $3(b)$ ). Discocytes were bi-concave to varying degrees and preserved the teeth. The central concavity depth and curvature varied: the ratio of the erythrocyte diameter and the incurvation diameter differed significantly compared to the control value: $16 \pm 4$ and $20 \pm 2$ units, respectively $(p<0.05)$. At the same time, there remained irreversibly deformed (prehemolytic) erythrocytes in the form of stomatocytes and degenerative forms of cells.

The ability to assess redistribution of optical density within the cell accurately is an important advantage of laser interference microscopy compared to other imaging methods. According to certain data [10], this method provides the possibility to present interference

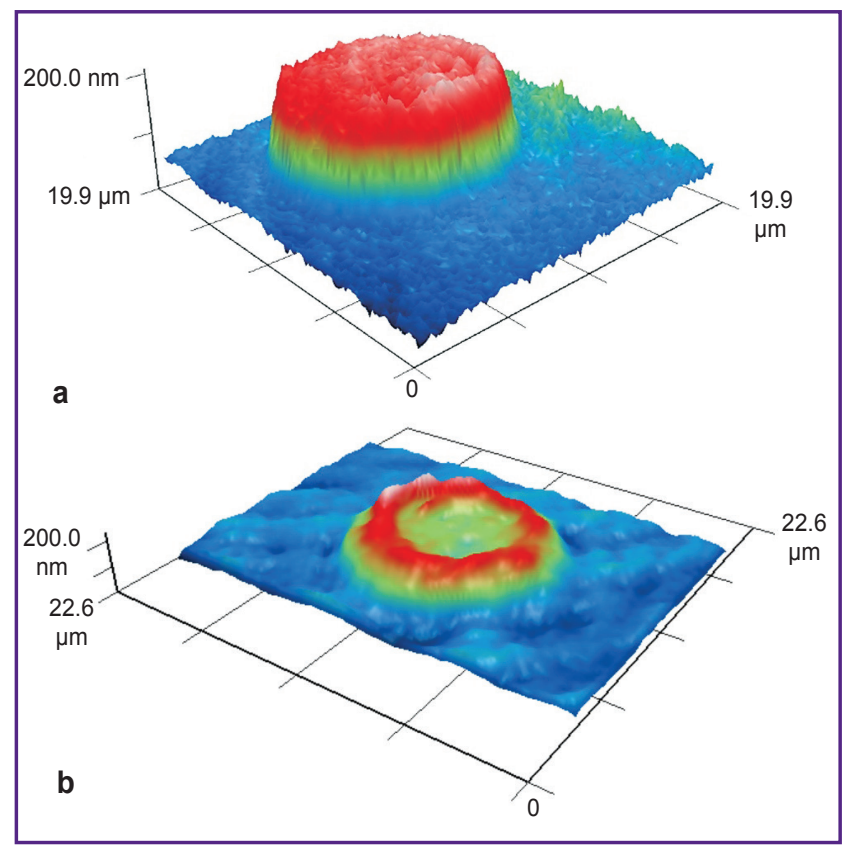

Figure 3. Phase-interference profiles of erythrocytes in stressed animals:

(a) before exposure to radiation; (b) under the action of LILR on blood samples 
images of color channels and the resulting color image (Figure 4).

Analysis of the obtained results shows that intact erythrocytes without exposure to radiation and after LILR are characterized by phase profile wavelengths ranging in the region of $500-600 \mathrm{~nm}$ in contrast to erythrocyte phase profile dominated by wavelength increase up to 600-650 nm in conditions of stress followed by LILR exposure. This dynamics may be associated with several processes occurring in cells. For example, characteristic absorption maxima for oxyhemoglobin $\left(\mathrm{HbO}_{2}\right)$ are observed at wavelengths of 541 and $576 \mathrm{~nm}$, they are also in the region of $500-600 \mathrm{~nm}$ for other hemoglobin forms with $\mathrm{Fe}^{2+}$. When iron oxidizes and the amount of ferrihemoglobin increases, there is a shift of the spectrum to $630 \mathrm{~nm}$ [11]. Besides, wavelength increase may indicate an increase in hemoglobin packaging density. In particular, molecular aggregation significantly changing physical and chemical properties of substances is found to be most characteristic of porphyrins [12]. It should also be taken into account that the change in phase profile may be associated with changes in intracellular metabolic products in the cell [13]. It is demonstrated that the shift of the spectrum to $650 \mathrm{~nm}$ is observed due to increase in $\mathrm{H}_{2} \mathrm{O}_{2}$ [13]. In our experiments, the analysis of oxidative metabolism by MDA concentration and energy processes by ATP content revealed a significant increase in oxidative processes in the cell under stress (3 times more compared to intact samples) and a decrease in energy parameters (2 times less compared to intact cells) (see the Table). Metabolic processes were restored through exposure to LILR in conditions of stress, but did not reach the level of intact cells.

Enhancement of LPO (lipid peroxidation) under stress is considered to be a well-established mechanism of cell damage [14]. The increase of pro-oxidant processes impairs the state of lipid and protein components, which may affect cell viability and morphology $[15,16]$. LILR is

MDA and ATP concentrations in erythrocytes in the groups under study $(\mathrm{M} \pm \mathrm{m})$

\begin{tabular}{lcc}
\hline Groups under study & MDA $(\mathrm{nmol} / \mathrm{ml})$ & ATP $(\mu \mathrm{mol} / \mathrm{ml})$ \\
\hline Intact & $1.91 \pm 0.33$ & $1.09 \pm 0.34$ \\
\hline Intact + LILR & $1.14 \pm 0.31^{*}$ & $0.79 \pm 0.32$ \\
Stress & $3.04 \pm 0.49^{*}$ & $0.57 \pm 0.26^{*}$ \\
\hline Stress + LILR & $2.54 \pm 0.23^{+}$ & $1.87 \pm 0.27^{*+}$ \\
\hline
\end{tabular}

Note: * statistically significant value differences compared to intact group indices; + compared to "stress" group indices; $p<0.05$. found to be capable of reducing LPO processes, having a normalizing effect on the liquid crystal structure of the lipid bilayer, which inhibits LPO processes [17]. Analysis of erythrocyte surface structure by laser interference microscopy revealed increase in membrane surface roughness under stress (Figure 5), which is likely to be due to increased lipid peroxidation and protein phase impairment, while restoration of surface architectonics under the action of LILR correlates with inhibition of oxidation processes.

\section{Conclusion}

Obtained by laser interference microscopy, the phase pattern of erythrocytes exposed to low-intensity laser radiation in conditions of stress shows changes in erythrocyte morphology accompanied by redistribution of cell density and their surface architectonics, which may depend on metabolic activity of erythrocytes.

The use of laser interference microscopy is a good alternative to classical microfluorimetry. The obtained images of erythrocytes allow us to study cell morphology and relief associated with their physiological metabolic state, which makes it possible to analyze the physiological status of cells.

Study funding. The study was supported by the Russian Foundation for Basic Research within the framework of scientific project 18-016-00195.

Conflict of interests. The authors have no conflict of interests to disclose. 


\section{EXPERIMENTAL INVESTIGATIONS}

\section{References}

1. Sudakov K.V. Evolution of the stress concept. Vestnik Rossiyskoy akademii meditsinskikh nauk 2008; 11: 59-66.

2. Musikhin L.V., Shvetskiy F.M., Khosrovyan A.M., Molotova N.L., Bugrovskaya O.I., Smol'nikov P.V., Shiryaev V.S. Some aspects of the use of low-intensity laser radiation in anesthetic practice. Vestnik intensivnoy terapii 2009; 3: 75-83.

3. Babaev A.V., Gogolev D.E., Reiner O.V., Korochkin I.M., Fandeev A.V., Pivovarov V.Y., Fedulaev Y.N., Drachan K.M. Effect of intravenous low-intensity laser irradiation of the blood on clinical and laboratory parameters of hepatocellular insufficiency. Bull Exp Biol Med 2012; 153(5): 754-757, https:// doi.org/10.1007/s10517-012-1818-1.

4. Luo G.-Y., Sun L., Liu T.C.-Y. Aquaporin-1-mediated effects of low level $\mathrm{He}-\mathrm{Ne}$ laser irradiation on human erythrocytes. International Journal of Photoenergy 2012; 2012: 1-5, https://doi.org/10.1155/2012/275209.

5. Ignat'ev P.S. Lazernaya interferentsionnaya mikroskopiya morfologii i dinamiki biologicheskikh ob"ektov $v$ real'nom vremeni. Avtoref. dis. ... kand. fiz.-mat. nauk [Laser interference microscopy of morphology and dynamics of biological objects real-time. PhD Thesis]. Moscow; 2011.

6. Krylov V.N., Deriugina A.V., Pleskova S.N., Kalinin V.A. Apoptotic nature of erythrocyte hemolysis induced by low doses of ionizing radiation. Biophysics 2015; 60(1): 79-84, https://doi.org/10.1134/s0006350915010170.

7. Vinogradova I.L., Bagryantseva S.Yu., Derviz G.V. Method of simultaneous determination of 2,3 DPG and ATP in erythrocytes. Laboratornoe delo 1980; 7: 424-426.

8. Boyarinov G.A., Yakovleva E.I., Zaitsev R.R., Bugrova M.L., Boyarinova L.V., Solov'eva O.D., Deryugina A.V., Shumilova A.V., Filippenko E.S. Pharmacological correction of microcirculation in rats suffering from traumatic brain injury. Cell and Tissue Biology 2017; 11(1): 65-72, https://doi. org/10.1134/s1990519x17010023.

9. Berestovskaya Y.Y., Gerasimenko L.M., Yusipovich A.I., Maksimov G.V., Rubin A.B., Levin G.G., Shutova V.V. New possibilities of studying microbial objects by laser interference microscopy. Biophysics 2011; 56(6): 1063-1068, https://doi org/10.1134/s0006350911060224.

10. Dyachenko A.A., Ryabukho V.P. Measurement of the optical thickness of a layered object from interference colors in white-light microscopy. Computer Optics 2017; 41(5): 670679, https://doi.org/10.18287/2412-6179-2017-41-5-670-679.

11. Erstenyuk A.M. Ligand forms of hemoglobin in the dynamics of cadmium intoxication. Mikroelementy $v$ meditsine 2012; 13(2): 8-13.

12. Würthner F., Kaiser T.E., Saha-Möller C.R. J-aggregates: from serendipitous discovery to supramolecular engineering of functional dye materials. Angew Chem Int Ed Engl 2011; 50(15): 3376-3410, https://doi.org/10.1002/anie.201002307.

13. Lobanov A.V., Nevrova O.V., Barzilovich P.Yu. Roubtsova N.A., Komissarov G.G. Interaction of metal porphyrins and hydrogen peroxide: coordination, photocatalysis and electron transfer. In: Islamova R.M., Kolesov S.V., Zaikov G.E. (editors). Kinetics, catalysis and mechanism of chemical reactions. From pure to applied science. Vol. 2. Tomorrow and perspectives. New York: Nova Science Publishers; 2012; p. 305-311.

14. Mironov V.A., Filippov A.V., Shirshikov F.V., Cherepnev G.V., Kalacheva N.V. The effect of binase on the necrosis and apoptosis of macrophages in an oxidative stress model. Uchenye zapiski Kazanskogo universiteta. Seriya: Estestvennye nauki 2012; 154(2): 66-76.

15. Kontorshchikova K.N., Vedunova M.V., Makarova E.S., Orlov B.Yu. Influence of doxorubicin, ozone and oxygen on the viability of normal and malignant liver cells in culture. Vestnik fizioterapii i kurortologii 2016; 22(2): 10-11.

16. Alyasova A.V., Terentiev I.G., Tsybusov S.N., Vedunova M.V., Mishchenko T.A., Shakhova K.A. Kontorshchikova K.N. Novel notions of the mechanisms of action of doxorubicin and ozone on malignant hepatic cells. Sovremennye tehnologii $v$ medicine 2017; 9(2): 145, https:// doi.org/10.17691/stm2017.9.2.18.

17. Srubilin D.V., Enikeeva D.A., Isakov I.D. The structuralfunctional damages of erythrocytes and their correction by low intensive laser radiation in subchronic intoxication with dichlorethane. Vestnik novyh medicinskih tehnologij 2012; 19(4): 105-108. 